\title{
Association between Cytochrome P450 2 C9 and Vitamin K Epoxide Reductase Complex Subunit 1 Polymorphisms with Warfarin Dose among Iranian Patients
}

\author{
Reyhaneh kameli ${ }^{1,3}$, Mandana Hasanzad ${ }^{2}$, Zahra Tahmasebi Fard ${ }^{4}$, Mojgan Babanejad ${ }^{3}$, Mahdieh Imeni ${ }^{1,3}$, Lotfollah Feizi Barnaji ${ }^{3}$, \\ Atoosa Madadkar ${ }^{3}$, Seyed Hamid Jamaldini ${ }^{5 *}$ \\ 1 Biology Department, Islamic Azad University of pharmaceutical sciences, Tehran, Iran. \\ 2 Medical Sciences Research Center, Tehran Medical Branch, Islamic Azad University, Tehran, Iran. \\ 3 Cardiogenetics Research Center, Shahid Rajaei Cardiovascular Medical and Research Center, Tehran, Iran. \\ 4 Department of biology, Roudehen Branch, Islamic Azad University, Roudehen, Iran. \\ 5 Applied biotechnology research Center, Tehran Medical sciences Branch, Islamic Azad University, Tehran, Iran.
}

\author{
Received: \\ Revised : \\ Accepted: \\ Corresponding Author: \\ Seyed Hamid Jamaldini \\ Applied biotechnology research \\ Center, Tehran Medical sciences \\ Branch, Islamic Azad University, \\ Tehran, Iran. \\ Phone: +9126152861 \\ E-mail: hjam1358@yahoo.co.uk
}

\begin{abstract}
Background: Warfarin is a common anticoagulant drug that has a narrow therapeutic index; higher dose causes excessive bleeding and lower dose leads to cerebrovascular clotting and stroke in patients. Genetic factors that have been associated with warfarin response are the genes of cytochrome P450 2C9 (CYP2C9), which metabolize the more active S-enantiomer of warfarin, and vitamin $\mathrm{K}$ epoxide reductase (VKOR), the target site for warfarin. The present study was conducted to investigate the association between CYP2C9*2, CYP2C9*3 and VKORC1 (-1639 G>A) polymorphisms with warfarin daily dose on 118 Iranian patients under warfarin treatment.

Materials and Methods: This study is comprised of 118 Iranian patients on warfarin treatment who attended the PT Clinic. Genotyping of CYP2C $9 * 2$, CYP2C9*3 and VKORC1 (-1639 G>A) was performed by PCR-RFLP method. Multiple regression model was performed for statistical analyses and $\mathrm{P}<0.05$ was considered as significance level.

Results: The allelic frequencies of CYP2C9*2 and CYP2C9*3 were $19 \%$ and $7 \%$, respectively. Patients with $\geq 1$ CYP2C9 variant allele had a significantly lower mean warfarin daily dose compared with patients with the wild-type genotype. The allelic frequencies of VKORC1 were $14.4 \%, 57.6 \%$ and $27.9 \%$ for GG, GA, and AA genotypes, respectively. The mean (SD) warfarin daily dose in patients with the VKORC1 (-1639) GG genotype was significantly higher than GA and AA patients.

Conclusion: CYP2C9*2, CYP2C9*3 and VKORC1 (-1639 G>A) polymorphisms had significant association with warfarin daily dose. Furthermore, the daily warfarin dose was not influenced by age, height, weight and sex.
\end{abstract}

Keywords: CYP2C9*2; CYP2C9*3; VKORC1; Warfarin; RFLP

Please cite this article as: kameli R, Hasanzad M, Tahmasebi Fard Z, Babanejad M, Imeni M, Feizi Barnaji L, Madadkar A, Jamaldini SH. Association between Cytochrome P450 2 C9 and Vitamin K Epoxide Reductase Complex Subunit 1 Polymorphisms with Warfarin Dose among Iranian Patients. Res Mol Med. 2016; 4 (4): 38-44

\section{Introduction}

Warfarin is a common drug used for the prevention of coagulation in patients with heart disease. Warfarin is a potent inhibitor of the vitamin $\mathrm{K}$ epoxide reductase (VKOR) encoded by the vitamin $\mathrm{K}$ epoxide reductase complex subunit 1 (VKORC1) gene $(1,2)$. Warfarin exerts its anticoagulant effects by inhibiting the ability of VKOR enzyme to recycle vitamin $\mathrm{K}$ epoxide to vitamin $\mathrm{K}$ hydroquinone (KH2) (3). Thus, warfarin inhibits coagulation pathway by preventing the vitamin K cycle (4). The International normalized ratio (INR) is a standard index for monitoring of coagulation. An INR value between 2 
and 3 is regarded as the therapeutic range for an individual (5). Warfarin has a narrow therapeutic rang. This narrow window range means that patients may suffer from bleeding when INR be upper than therapeutic range and thrombosis when INR be under therapeutic range $(6,7)$. There is substantial interindividual variability in the warfarin dose needed to achieve optimal anticoagulation. Age, weight, height, vitamin $\mathrm{K}$ intake, and the use of concomitant medications that affect warfarin metabolism and disposition are a number of nongenetic factors known to influence warfarin dose requirements $(8,9)$.

Genetic factors have been associated with warfarin response are the genes for cytochrome P450 2C9 (CYP2C9), which metabolize the more active Senantiomer of warfarin, and vitamin $\mathrm{K}$ epoxide reductase (VKOR), the target site for warfarin. Specifically, the CYP2C9*2 (R144C; rs1799853) allele in exon 3 and *3 (I359L; rs1057910) allele in exon 7 result in reduced CYP2C9 enzyme activity and lower warfarin dose requirements compared to the CYP2C $9 * 1 / * 1$ genotype $(10,11)$. The $-1639 \mathrm{G}>\mathrm{A}$ (rs9923231) polymorphism located in the VKOR complex-1 (VKORC1) gene promoter region has been correlated with 2-fold lower level of VKORC1 mRNA and lower warfarin dose requirements in predominately European Caucasian and Asian populations (12).

The clearance of drugs that has been eliminated by CYP2C9 has become increased by the treatment with rifampicin. In healthy subjects or patients who have been treated with rifampicin, the clearance of losartan, phenytoin, tolbutamide and S-warfarin is almost doubled (13).

Amiodarone, fluconazole and sulphaphenazole can inhibit CYP2C9. When an inhibitor is added to a therapeutic regime that includes drugs like warfarin, tolbutamide and phenytoin, then we face with drugdrug interaction (14). For example, There are different studies that indicated drug interaction between warfarin and amiodarone $(15,16)$.

\section{Materials and methods \\ Study population and data collection}

Enrolled subjects were Iranian patients on warfarin treatment who attended the PT Clinic at Shahid Rajaei cardiovascular and research center for regular INR monitoring from July to October 2012. After obtaining informed consent, these candidates were asked to fill out a questionnaire which contained demographic characteristics inclusive of sex, age, height, weight, ethnicity, use of any concomitant drugs, cause of warfarin therapy, daily warfarin dose requirement and all INR measurements during the three subsequent weeks. All patients had to be aged $\geq 18$ years (Our patients were in the range of $18-87$ years old). The recruited subjects had to achieve a stable INR in the target range of 2 to 3.5 at least during three consecutive months.

Patients in the study were excluded if: they had received any concurrent therapy known to interfere the anticoagulant effect of warfarin clinical evidence, showed hyperthyroidism or hypothyroidism, hepatic disease or dysfunction, or renal disease or dysfunction (17).

\section{Genotyping}

Genotyping of CYP2C9*2, CYP2C9*3 and VKORC1 (-1639 G>A) were performed by PCRrestriction fragment length polymorphism. The CYP2C9*3 allele was analyzed by amplification of a fragment including an NsiI restriction site present in the wild type allele but absent in the CYP2C9*3 allele because of the I359L mutation. The CYP2C $9 * 2$ allele was resistant to cleavage by AvalI and remained at $454 \mathrm{bp}$. The wild type allele, cleaved into two fragments of $400 \mathrm{bp}$ and $54 \mathrm{bp}$. For VKORC1 the amplified products (290 bp) were digested with a MspI restriction enzyme which produced a 124-and a 166- bp fragment in the absence of mutant allele. Primers and PCR product sizes for VKORC1 and CYP2C9 are shown in Table 5.

Table 5. Primers sequence and fragments length

\begin{tabular}{lll}
\hline Polymorphism & Primers sequence & Fragments length \\
\hline CYP2C9*2 & $\begin{array}{l}\text { gTATTTTggCCTgAAACCCATA } \\
\text { ggCCTTggTTTTCTCAACTC }\end{array}$ & $454 \mathrm{bp}$ \\
CYP2C9*3 & TGTGGTGCACGAGGTCCAGAGAT & \\
& ACCCGGTGATGGTAGAGGT & $188 \mathrm{bp}$ \\
VKORC1 & gCCAgCAggAgAgggAAATA & \\
& AgTTTggACTACAggTgCCT & $290 \mathrm{bp}$ \\
\hline
\end{tabular}

For CYP2C9*2 and CYP2C9*3, PCR was performed with an initial denaturation at $94{ }^{\circ} \mathrm{C}$ for 5 minutes, followed by 35 cycles of denaturation $\left(94^{\circ} \mathrm{C}\right.$ for 1 minute), annealing $\left(57^{\circ} \mathrm{C}\right.$ for 1 minute), elongation $\left(72{ }^{\circ} \mathrm{C}\right.$ for 1 minute), and final extension $\left(72{ }^{\circ} \mathrm{C}\right.$ for 5 minutes). For VKORC1 the PCR condition was 
similar, but annealing was performed at $60{ }^{\circ} \mathrm{C}$ for 1 minute.

\section{Results}

Hardy Weinberg equilibrium test for CYP2C9 * 2, CYP2C9 * 3 and VKORC1 polymorphisms was performed and according to the p-values of 0.651, 0.068 and 0.058 respectively, the Population was in Hardy Weinberg equilibrium. The relationship between warfarin dose and CYP2C9 polymorphisms was tested using the Kruskal-Wallis test. All tests were performed using SPSS, (version 16.0). $\mathrm{P}<0.05$ was considered significant.

The allelic frequencies of CYP2C $9 * 2$ and CYP2C $9 * 3$ were $19 \%$ and $7 \%$ respectively. Two groups of CYP2C 9 genotypes were considered: CYP2C $9 * 1 / * 1$ (wild type) and CYP2C9X/Y (patients with $\geq 1$ variant allele). Patients with $\geq 1$ variant allele $(n=79)$ had a significantly lower mean warfarin daily dose compared with patients with the wild-type genotype.

The allelic frequencies of VKORC1 were $14.4 \%$ (17/118), 57.6\% (68/118), and 27.9\% (33/118) for GG, GA, and AA genotypes, respectively. The mean (SD) warfarin daily dose was $6.02 \mathrm{mg}$ in patients with the VKORC1 (-1639) GG genotype. This was significantly higher than the weekly dose among those with the GA genotype $(5.13 \mathrm{mg})$ or the AAgenotype $(4.06 \mathrm{mg})$. Regression analysis models were designed for patients who had all demographic variables and allelic frequencies of the three enzymes available.

Table 1. Characteristics of studied patients.

\begin{tabular}{lll}
\hline Variables & values & Standard Derivation \\
\hline Sex, no & & \\
Men & 42 & \\
Women & 76 & \\
Age, year & 57.8 & \\
Mean & $18-87$ & 14.03 \\
Range & 68.6 & \\
Weight, kg & $40-105$ & 14.12 \\
Mean & & \\
Range & & \\
Height, cm & 164.4 & 10.31 \\
Mean & $142-193$ & \\
Range & & 1.91 \\
Daily warfarin dose, mg & 4.98 & \\
Range & $1.25-10.89$ & \\
\hline
\end{tabular}

Multiple linear regression analysis found that sex $(\mathrm{P}$ $=0.717)$, height $(\mathrm{P}=0.925)$, weight $(\mathrm{P}=0.769)$, ethnicity $(\mathrm{P}=0.270)$ and age $(\mathrm{P}=0.188)$ had no significant influence on the maintenance dose of warfarin whereas CYP2C9 and VKORC1 polymorphisms had the greatest effects on the warfarin maintenance dose requirement. Characteristics of studied patients are mentioned in Table 1 and the distribution of CYP2C9 and VKORC1 genotypes in patients receiving warfarin are shown in Table 2.

\section{Discussion}

Warfarin is a well-accepted drug for many clinical conditions. However, it has a narrow therapeutic index; higher dose is the cause of excessive bleeding and lower dose leads to cerebrovascular clotting and stroke in patients. Many reports demonstrated some relationships between warfarin dose and warfarin sensitivity genotype $(6,11,18)$. The two genes showing the greatest interaction with variation in warfarin dose are CYP2C9 and VKORC1. Combined, polymorphisms in these two alleles plus age, sex, and weight account for $56 \%$ to $64 \%$ of warfarin dose variation (19).

There are substantial differences in the frequencies of CYP2C9*2 and CYP2C9*3 allelic variants among different populations $(20,21)$. Our results indicated that most $(66.9 \%)$ of Iranian participants had wildtype CYP2C9, 19\% carried CYP2C9*2 allele and 7\% had CYP2C9*3.

Previous published study introduced CYP2C9*2 variant as the most common mutant allele among Caucasians (10-13\%), the present study found a slightly higher frequency (19\%); this finding is different from previous study that reported the 
frequency of $10-13 \%$ in other Caucasians, $0 \%$ in Japanese and 2\% in Africans $(19,22)$.

Table 2. Distribution of CYP2C9 and VKORC1 genotypes in patients receiving warfarin

\begin{tabular}{|c|c|c|c|}
\hline Genotype & Frequency & Percent & $\begin{array}{l}\text { Mean warfarin dose } \\
\text { (mg/day) }\end{array}$ \\
\hline CYP $2 C 9 * 1 / * 1$ & 79 & 0.669 & 5.37 \\
\hline$C Y P 2 C 9 * 1 / * 2$ & 21 & 0.178 & 4.68 \\
\hline$C Y P 2 C 9 * 1 / * 3$ & 14 & 0.119 & 3.81 \\
\hline$C Y P 2 C 9 * 2 / * 2$ & 1 & 0.008 & 3.75 \\
\hline CYP2C $9 * 2 / * 3$ & 2 & 0.016 & 2.76 \\
\hline CYP2C9*3/*3 & 1 & 0.008 & 1.78 \\
\hline VKORC1 GG & 17 & 0.144 & 6.02 \\
\hline VKORC1 GA & 68 & 0.576 & 5.13 \\
\hline VKORC1 AA & 33 & 0.279 & 4.06 \\
\hline
\end{tabular}

The observed frequency for CYP2C9*3 was 7\% in the present study. This finding was similar to the other Caucasian frequency (6-9\%) but different from the frequency found in Japanese $(2.3 \%)$ and Africans
(1\%) $(21,23)$. A comparison between CYP2C9 allele and genotype frequencies of different populations are summarized in Table 3 .

Table 3. A summary of CYP2C $9 * 2$ and CYP2C $9 * 3$ allelic variant* frequencies of different population.

\begin{tabular}{lllllllll}
\hline CYP2C9 & Present Study (\%) & Italy $(\%)$ & Sweden $(\%)$ & British (\%) & UK (\%) & Dutch (\%) & Japan (\%) & African (\%) \\
\hline$* 1$ & 61 & 77.7 & 81.9 & 79 & 84.1 & 76.6 & 97.6 & 9 \\
$* \mathbf{2}$ & 19 & 12.5 & 10.6 & 12.5 & 10.6 & 14.2 & 0 & 2 \\
$* 3$ & 7 & 9.7 & 7.4 & 8.5 & 5.2 & 9.2 & 2.3 & 1 \\
Reference & & $(20)$ & $(23)$ & $(25)$ & $(35)$ & $(38)$ & $(39,40)$ & $(40)$ \\
\hline
\end{tabular}

In the present study, as it was expected, the frequencies of homozygotes for the CYP2C9*2 and CYP2C9*3 variants were low (both $0.8 \%$ ). The frequencies of the two heterozygous genotypes CYP2C9*1/*2 and CYP2C9*1/*3 were $17.8 \%$ and $11.9 \%$, respectively, whereas compound heterozygotes of $\mathrm{CYP} 2 \mathrm{C} 9 * 2 / * 3$ was $1.6 \%$. Our results are consistent with those of Caucasian population which was studied by Hauge et al. (2008) (24). They evaluated the genotype distributions of CYP2C9*2 and CYP2C9*3 polymorphisms in 212 patients and found that the genotype frequency of the CYP2C $9 * 1 / * 2$ variant was $17.9 \%$, whereas the CYP2C9*1/*3 variant was $9.4 \%$. Homozygotes of the CYP2C $9 * 2$ and $\mathrm{CYP} 2 \mathrm{C} 9 * 3$ variant constituted
$1.9 \%$ and $0.5 \%$ of the patients, respectively and CYP2C9 compound heterozygotes (CYP2C9*2/*3) was $0.9 \%$.

In a study in Taiwan (18) $0.4 \%$ of 92 white subjects were homozygotes for CYP2C9*3 alleles; in another study in United Kingdom one of 297 patient had CYP2C $9 * 3 / * 3$, wich is consistent with our findings in that this genotype was found in one patient of Iranian subjects (25).

We found that those who had the wild-type variant of CYP2C9 needed a significantly higher mean dose of warfarin $(5.37 \mathrm{mg} / \mathrm{d})$ compared with others. The second group belongs to patients who carried one mutation in CYP2C9 gene. In this group, patients with CYP2C $* 1 / * 2$ needed higher mean dose of 
warfarin $(4.76 \mathrm{mg} / \mathrm{d})$ than CYP2C $9 * 1 / * 3 \quad(3.84$ $\mathrm{mg} / \mathrm{d}$ ). The Third group belongs to patients who carried more than one mutation in CYP2C9 gene. This group included patients with CYP2C $9 * 2 / * 2$, CYP2C $9 * 2 / * 3$ and CYP2C $9 * 3 / * 3$ genotype who needed $3.75 \mathrm{mg} / \mathrm{d}, 2.76 \mathrm{mg} / \mathrm{d}$ and $1.87 \mathrm{mg} / \mathrm{d}$, respectively. Previous studies showed that $* 2$ and *3 polymorphisms are associated with reduced metabolism of warfarin; Margaglione et al. (2000) reported similar observations in 180 Italian patients followed up at one specialized clinic from the start of the anticoagulation with warfarin. Required dose of warfarin in patients with CYP2C9*1 haplotype (5.6 $\mathrm{mg} / \mathrm{d})$, was more than those carried CYP2C $9 * 2(4.7$ $\mathrm{mg} / \mathrm{d})$ and $\mathrm{CYP} 2 \mathrm{C} 9 * 3 \quad(4.0 \mathrm{mg} / \mathrm{d})$ haplotypes. Patients who had both CYP2C9*2 and CYP2C9*3 haplotypes, with $1.8 \mathrm{mg} / \mathrm{d}$ warfarin dose were in therapeutic INR range (26).
The frequencies of different VKORC1 $-1639 \mathrm{G}>\mathrm{A}$ alleles differ among Asian, African-American and Caucasian populations (18). The VKORC1 haplotype group A that leads to low warfarin dose requirement was the highest in Asian populations (89\%), whereas haplotype group B was the highest in Caucasian populations (58\%) (27).

Our results showed that $14.4 \%$ of participants carried a GG genotype, whereas the AA and GA genotypes were seen in $27.9 \%$ and $57.6 \%$ of participants, respectively. The frequency of the $-1639 \mathrm{~A}$ and $1639 \mathrm{G}$ alleles were estimated as $56.7 \%$ and $43.2 \%$, respectively; this result agrees with reports from the other Caucasians and Hispanics but is different ( $\mathrm{p}<$ 0.05 ) from the frequencies seen among Asians and in African American populations. A comparison between VKORC1 allele and genotype frequencies among different ethnics is summarized in Table 4 (28).

Table 4. Comparison between VKORC1 allele and genotype frequencies among different ethnics.

\begin{tabular}{|c|c|c|c|c|c|}
\hline $\begin{array}{l}\text { VKORC1 } \\
-1639 G>\text { A genotype }\end{array}$ & $\begin{array}{l}\text { African-American } \\
(\mathrm{n}=\mathbf{3 0 0})\end{array}$ & $\begin{array}{l}\text { Asian } \\
(\mathrm{n}=102)\end{array}$ & $\begin{array}{l}\text { Caucasian } \\
(\mathrm{n}=106)\end{array}$ & $\begin{array}{l}\text { Hispanic } \\
(\mathrm{n}=101)\end{array}$ & $\begin{array}{l}\text { Present study } \\
(n=118)\end{array}$ \\
\hline$G G$ & 80.3 & 22.5 & 36.8 & 30.7 & 14.4 \\
\hline $\boldsymbol{G A}$ & 17.7 & 21.6 & 45.3 & 51.5 & 57.6 \\
\hline $\boldsymbol{A} \boldsymbol{A}$ & 2.0 & 55.9 & 17.9 & 17.8 & 27.9 \\
\hline \multicolumn{6}{|l|}{$\begin{array}{l}\text { VKORC1 } \\
-1639 G>A \text { Allele }\end{array}$} \\
\hline G & 89.5 & 33.3 & 59.45 & 56.45 & 56.7 \\
\hline $\mathbf{A}$ & 10.85 & 66.7 & 40.55 & 43.55 & 43.2 \\
\hline
\end{tabular}

In another study in Mazandaran province of Iran a total of 29 patients taking warfarin were studied. The objective of study was to determine the influence of 3 VKORC1 polymorphisms $(-1639 \mathrm{G}>\mathrm{A}, 1173 \mathrm{C}>\mathrm{T}$ and $3730 \mathrm{G}>\mathrm{A})$ on warfarin dose requirement. Significant correlation was obtained only between $-1639 \mathrm{G}>\mathrm{A}$ polymorphism and warfarin dose requirement. In this polymorphism, 25 patients $(86.2 \%)$ were AA, 2 patients $(6.9 \%)$ were GA and 2 patients $(6.9 \%)$ were GG genotype. Mean dose of warfarin in patients with AA genotype was lower but their INR was higher than the other two genotypes (29).

Our results suggest that VKORC1 polymorphism may have a greater effect on warfarin dose than CYP2C9 polymorphism, and this is in accordance with the findings of previous studies. RHaug et al. studied 105 Norwegian patients of Caucasian race and the findings confirmed that the VKORC1 polymorphism had a larger impact $(25 \%)$ compared to CYP2C9 (7\%) (24). Another study by Herman et al. which analyzed 165 Slovenians showed that VKORC1 contributed 34\% and CYP2C9 18\% (22). Based on a review article by Wadelius and Pirmohamed, six studies found that VKORC1. had a greater effect on warfarin dose than CYP2C9 (30-33). In contrast, two studies which were performed by Scon et al. and D'Andrea et al., found the greatest effect of CYP2C9 $(34,35)$ and one study by Vecsler et al. reported equal contribution of the two polymorphisms (21). Previous studies reported the influence of age on warfarin dose requirement but we failed to find any association between age and dose of warfarin. For example, a study of 297 patients on stable warfarin doses reported that mean warfarin daily dose requirements fell by 0.5 to $0.7 \mathrm{mg}$ per decade between the ages of 20 to 90 years (35). In another study of 115 African American stable patients, it was observed that CYP2C9 genotype, age, and body surface area account for $33 \%$ of the warfarin dose variability, whereas VKORC1 seemed to have no effect on warfarin dose (28). Hossam et al. studied 207 Egyptian patients taking warfarin for more than two months (36). VKORC1 genotype $(\mathrm{P}<$ $0.0001)$, CYP2C9 gene $(\mathrm{P}=0.0004)$ and increasing age $(\mathrm{P}<0.0001)$ were associated with warfarin doses. Similar to our observation height and weight were not significant predictors of dose; in our study height and weight didn't have any association with the dose 
requirement either. Furthermore, in regard to $\mathrm{P}=$ 0.717 and $\mathrm{P}=0.270$ for sex and ethnicity respectively, these two factors had no influence on warfarin dose. These findings are similar to the findings of a study that was conducted in 2010 in wich sex $(\mathrm{P}=0.36)$, weight $(\mathrm{P}=0.75)$, body mass index $(\mathrm{BMI})(\mathrm{P}=0.67)$ and height $(\mathrm{P}=0.55)$ had no influence on warfarin dose (37).

\section{Conclusion}

Warfarin has been one of the most important coagulation drugs for a long time. Despite its efficiency,the possibility of bleeding in sensitive patients, makes it difficult to be used. Warfarin sensivity has a multigenic and multifactorial inheritance. However, a combination of genetic polymophisms has the greatest contribution to warfarin sensivity. The correlation between the maintenance dose of warfarin and allelic variants of CYP2C9 and VKORC1 has been demonstrated by many previous studies and is reconfirmed in this report.

The present study found a higher frequency for CYP2C9*2 (19\%) than those previously found in other Caucasians. For CYP2C9*3, the frequency of $7 \%$ found in the present study was similar to the reports on other Caucasians. The frequency of the $1639 \mathrm{~A}$ and $-1639 \mathrm{G}$ alleles were estimated $56.7 \%$ and $43.2 \%$, respectively; this result agrees with reports from the other Caucasians. Moreover, our study showed that CYP2C9 and VKORC1 polymorphisms had significant influence on Iranian daily warfarin dose, but the effect of age was not significant. Height and weight did not have a significant correlation with the warfarin maintenance dose. In addition, there was no significant relationship between sex, ethnicity and the maintenance dose of warfarin (the data are not shown).

Understanding the pharmacogenetics involved in warfarin variability, helps physicians to prescribe appropriate dose that prevents bleeding or clotting effects. If such studies improve the outcomes of therapy, then more investigations lead to design algorithms that present a new way to achieve therapeutic INR in a rapid and easy manner.

\section{Acknowledgments}

We acknowledge all the collaborators who helped us for gathering data. We thank Biology Department of Islamic Azad University of pharmaceutical sciences and Cardiogenetics Research Center of Shahid Rajaie Cardiovascular Medical \& Research Center for their support.

\section{References}

1. Li T, Chang C-Y, Jin D-Y, Lin P-J, Khvorova A, Stafford DW. Identification of the gene for vitamin K epoxide reductase. Nature.

\section{4; 427(6974):541-4. PMID: 14765195}

2. Rost S, Fregin A, Ivaskevicius V, Conzelmann E, Hörtnagel K, Pelz H-J, et al. Mutations in VKORC1 cause warfarin resistance and multiple coagulation factor deficiency type 2. Nature. 2004; 427(6974):537-41. PMID: 14765194

3. Eriksson N, Wadelius M. Prediction of warfarin dose: why, when and how? Pharmacogenomics. 2012; 13(4):429-40. PMID: 22379999

4. Suttie J. The biochemical basis of warfarin therapy. Adv Exp Med Biol. 1987.2143:3-16. PMID: 3310547

5. Consortium IWP. Estimation of the warfarin dose with clinical and pharmacogenetic data. N Engl J Med. 2009; 360(8):753-64. PMID: 19228618

6. Anderson JL, Horne BD, Stevens SM, Grove AS, Barton S, Nicholas ZP, et al. Randomized trial of genotype-guided versus standard warfarin dosing in patients initiating oral anticoagulation. Circulation. 2007; 116(22):2563-70. PMID: 17989110

7. Odén A, Fahlén M, Hart RG. Optimal INR for prevention of stroke and death in atrial fibrillation: a critical appraisal. Thrombosis research. 2006; 117(5):493-9. PMID: 16517250

8. Absher RK, Moore ME, Parker MH. Patient-specific factors predictive of warfarin dosage requirements. Ann Pharmacother. 2002; 36(10):1512-7. PMID: 12243598

9. Ansell J, Hirsh J, Hylek E, Jacobson A, Crowther M, Palareti G. Pharmacology and management of the vitamin $\mathrm{K}$ antagonists: American College of Chest Physicians evidence-based clinical practice guidelines. Chest. 2008; 133(6 Suppl):160S-198S. PMID: 18574265

10. Aithal GP, Day CP, Kesteven PJ, Daly AK. Association of polymorphisms in the cytochrome P450 CYP2C9 with warfarin dose requirement and risk of bleeding complications. Lancet. 1999; 353(9154):717-9. PMID: 10073515

11. Higashi MK, Veenstra DL, Kondo LM, Wittkowsky AK, Srinouanprachanh SL, Farin FM, et al. Association between CYP2C9 genetic variants and anticoagulation-related outcomes during warfarin therapy.JAMA. 2002; 287(13):1690-8. PMID: 11926893

12. Wang D, Chen H, Momary KM, Cavallari LH, Johnson JA, Sadée W. Regulatory polymorphism in vitamin $\mathrm{K}$ epoxide reductase complex subunit 1 (VKORC1) affects gene expression and warfarin dose requirement. Blood. 2008; 112(4):1013-21. PMID: 18523153

13. Kanebratt K, Diczfalusy U, Bäckström T, Sparve E, Bredberg $\mathrm{E}$, Böttiger Y, et al. Cytochrome P450 Induction by Rifampicin in Healthy Subjects: Determination Using the Karolinska Cocktail and the Endogenous CYP3A4 Marker 4 $\beta$-Hydroxycholesterol. Clin Pharmacol Ther. 2008; 84(5):589-94. PMID: 18650803

14. Scheen AJ. Drug interactions of clinical importance with antihyperglycaemic agents. Drug Saf. 2005; 28(7):601-31. PMID: 15963007

15. Lu Y, Won KA, Nelson BJ, Qi D, Rausch DJ, Asinger RW. Characteristics of the amiodarone-warfarin interaction during longterm follow-up. Am J Health Syst Pharm. 2008; 65(10): 947-52. PMID: 18463344

16. Siddoway LA. Amiodarone: guidelines for use and monitoring. Am Fam Physician. 2003; 68(11):2189-96. PMID: 14677664 
17. Namazi S, Azarpira N, Hendijani F, Khorshid MB, Vessal G, Mehdipour AR. The impact of genetic polymorphisms and patient characteristics on warfarin dose requirements: a cross-sectional study in Iran. Clin Ther. 2010; 32(6):1050-60. PMID: 20637959

18. Yuan H-Y, Chen J-J, Lee MM, Wung J-C, Chen Y-F, Charng $\mathrm{M}-\mathrm{J}$, et al. A novel functional VKORC1 promoter polymorphism is associated with inter-individual and inter-ethnic differences in warfarin sensitivity. Hum Mol Genet. 2005; 14(13):174551.PMID: 15888487

19. Kealey C, Chen Z, Christie J, Thorn CF, Whitehead AS, Price $\mathrm{M}$, et al. Warfarin and cytochrome P450 2C9 genotype: possible ethnic variation in warfarin sensitivity. Pharmacogenomics. 2007; 8(3):217-25. PMID: 17324110

20. Scordo MG, Caputi AP, D'Arrigo C, Fava G, Spina E. Allele and genotype frequencies of CYP2C9, CYP2C19 and CYP2D6 in an Italian population. Pharmacol Res. 2004; 50(2):195-200. PMID: 15177309

21. Vecsler M, Loebstein R, Almog S, Kurnik D, Goldman B, Halkin $\mathrm{H}$, et al. Combined genetic profiles of components and regulators of the vitamin K-dependent?-carboxylation system affect individual sensitivity to warfarin. Thromb Haemost. 2006; 95(2):205-11. PMID: 16493479

22. Herman D, Peternel P, Stegnar M, Breskvar K, Dolzan V. The influence of sequence variations in factor VII, $\gamma$-glutamyl carboxylase and vitamin $\mathrm{K}$ epoxide reductase complex genes on warfarin dose requirement. Thromb Haemost. 2006; 95(5):782-7. PMID: 16676068

23. Yasar Ü, Eliasson E, Dahl M-L, Johansson I, IngelmanSundberg M, Sjöqvist F. Validation of methods for CYP2C9 genotyping: frequencies of mutant alleles in a Swedish population. Biochem Biophys Res Commun. 1999; 254(3):628-31. PMID: 9920790

24. Haug KB, Sharikabad MN, Kringen MK, Narum S, Sjaatil ST, Johansen PW, et al. Warfarin dose and INR related to genotypes of CYP2C9 and VKORC1 in patients with myocardial infarction. Thromb J. 2008; 6(1):7. PMID: 18559094

25. Van Booven D MS, McLeod H, Carrillo MW, Sangkuhl K, Klein TE, Altman RB. Cytochrome P450 2C9-CYP2C9. Pharmacogenet Genomics. 2010; 20(4):277-81. PMID: 20150829

26. Margaglione M, Colaizzo D, D'Andrea G, Brancaccio V, Ciampa A, Grandone E, et al. Genetic modulation of oral anticoagulation with warfarin. Thromb Haemost. 2000; 84(5):7758. PMID: 11127854

27. Rieder MJ, Reiner AP, Gage BF, Nickerson DA, Eby CS, McLeod HL, et al. Effect of VKORC1 haplotypes on transcriptional regulation and warfarin dose. N Engl J Med. 2005; 352(22):2285-93. PMID: 15930419

28. Scott SA, Khasawneh R, Peter I, Kornreich R, Desnick RJ Combined CYP2C9, VKORC1 and CYP4F2 frequencies among racial and ethnic groups. Pharmacogenomics. 2010; 11(6):781-91. PMID: 20504253
29. Salehifar E, Farhadi F, Janbabai G, Ahangar N. Effect of Three Main Polymorphisms of VKORC1 gene on Warfarin Dose Requirement in Patients from Mazandaran Province. Jo Maz Univ Med Sci. 2012; 22(94):44-52.

30. Aquilante CL, Langaee TY, Lopez LM, Yarandi HN, Tromberg JS, Mohuczy D, et al. Influence of coagulation factor, vitamin $\mathrm{K}$ epoxide reductase complex subunit 1 , and cytochrome P450 2C9 gene polymorphisms on warfarin dose requirements*. Clin Pharmacol Ther. 2006; 79(4). 291-302. PMID: 16580898

31. Geisen C, Watzka M, Sittinger K, Steffens M, Daugela L, Seifried E, et al. VKORC 1 haplotypes and their impact on the inter-individual and inter-ethnical variability of oral anticoagulation. Thromb Haemost. 2005; 94(4):773-9. PMID: 16270629

32. Lee SC, Ng SS, Oldenburg J, Chong PY, Rost S, Guo JY, et al. Interethnic variability of warfarin maintenance requirement is explained by VKORC1 genotype in an Asian population. Clin Pharmacol Ther. 2006; 79(3):197-205. PMID: 16513444

33. Wadelius M, Chen L, Downes K, Ghori J, Hunt S, Eriksson N, et al. Common VKORC1 and GGCX polymorphisms associated with warfarin dose. Pharmacogenomics J. 2005; 5(4):262-70. PMID: 15883587

34. D'Andrea G, D'Ambrosio RL, Di Perna P, Chetta M, Santacroce R, Brancaccio V, et al. A polymorphism in the VKORC1 gene is associated with an interindividual variability in the dose-anticoagulant effect of warfarin. Blood. 2005; 105(2):6459. PMID: 15358623

35. Sconce EA, Khan TI, Wynne HA, Avery P, Monkhouse L, King BP, et al. The impact of CYP2C9 and VKORC1 genetic polymorphism and patient characteristics upon warfarin dose requirements: proposal for a new dosing regimen. Blood. 2005; 106(7):2329-33. PMID: 15947090

36. Shahin MHA, Khalifa SI, Gong Y, Hammad LN, Sallam MT, El Shafey M, et al. Genetic and nongenetic factors associated with warfarin dose requirements in Egyptian patients. Pharmacogenet Genomics. 2011; 21(3):130. PMID: 21228733

37. Le Cam-Duchez V, Frétigny M, Cailleux N, Gandelin C, Lévesque $\mathrm{H}$, Borg J-Y. Algorithms using clinical and genetic data (CYP2C9, VKORC1) are relevant to predict warfarin dose in patients with different INR targets. Thromb Research. 2010; 126(3):e235-e7. PMID: 20569971

38. van der Weide J, Steijns LS, van Weelden MJ, de Haan K. The effect of genetic polymorphism of cytochrome P450 CYP2C9 on phenytoin dose requirement. Pharmacogenetics . 2001; 11(4):28791. PMID: 11434505

39. Mushiroda T, Ohnishi Y, Saito S, Takahashi A, Kikuchi Y, Saito S, et al. Association of VKORC1 and CYP2C9 polymorphisms with warfarin dose requirements in Japanese patients. J Hum Genet. 2006; 51(3):249-53. PMID: 16432637

40. Isaza C, Henao J, Martínez JHI, Arias JCS, Beltrán L. Phenotype-genotype analysis of CYP2C19 in Colombian mestizo individuals. BMC Clin Pharmacol. 2007; 7(1):6. PMID: 17623107 